\title{
Radiotherapy potentiation with weekly cisplatin compared to standard every 3 weeks cisplatin chemotherapy for locoregionally advanced head and neck squamous cell carcinoma
}

\author{
This article was published in the following Dove Press journal: \\ Drug Design, Development and Therapy \\ 26 November 2015 \\ Number of times this article has been viewed
}

\author{
Jérôme Fayette' \\ Yann Molin' \\ Emilie Lavergne ${ }^{2}$ \\ Xavier Montbarbon ${ }^{3}$ \\ Séverine Racadot ${ }^{3}$ \\ Marc Poupart ${ }^{4}$ \\ Antoine Ramade 5 \\ Philippe Zrounba ${ }^{6}$ \\ Philippe Ceruse ${ }^{7}$ \\ Pascal Pommier ${ }^{3}$ \\ 'Department of Medicine, \\ ${ }^{2}$ Biostatistics Unit, ${ }^{3}$ Department of \\ Radiotherapy, Centre Léon Bérard, \\ University of Lyon, ${ }^{4}$ Department \\ of Surgery, Hôpital Croix-Rousse, \\ ${ }^{5}$ Department of Surgery, Hôpital \\ Edouard Herriot, ${ }^{6}$ Department \\ of Surgery, Centre Léon Bérard, \\ University of Lyon, Lyon, France; \\ ${ }^{7}$ Department of Surgery, Centre \\ Hospitalier Lyon-Sud, Université de \\ Lyon, Pierre-Bénite, France
}

\begin{abstract}
Background: Despite its toxicity, cisplatin every 3 weeks ( $q 3 w$ ) is the standard potentiation of chemo-radiotherapy for head and neck squamous cell carcinoma. This study aimed to determine whether weekly cisplatin ( $\mathrm{q} 1 \mathrm{w})$ could be a safe and effective alternative.

Patients and methods: Two hundred and sixty-two patients with head and neck squamous cell carcinoma, irradiated in our institution with cisplatin (q1w or q3w) between January 2004 and December 2008, were retrospectively included. Overall survival (OS) and progression-free survival (PFS) were evaluated. Survival distributions were estimated by Kaplan-Meier method and compared using the log-rank test. Prognostic effect of chemo-radiotherapy was explored using Cox model.
\end{abstract}

Results: A total of 165 and 97 patients received q1w and q3w cisplatin, respectively. Median age, stage at diagnosis, alcohol consumption, intensity-modulated radiation therapy use, median weight, and renal failure before radiotherapy were significantly different, showing lower risk in the $\mathrm{q} 3 \mathrm{w}$ group. Q3w cisplatin was found to be more toxic in terms of weight loss, renal failure, worse chemotherapy plan completion, and grade $3 / 4$ mucositis and dermatitis, with more patients requiring analgesics, secondary hospitalization, and radiotherapy interruption ( $\geq 3$ days), and patients affected by long-term toxicities. With a median follow-up of 73 months (95\% confidence interval [CI] [68.9-76.2]), OS was found to be significantly better with q3w (5 years OS: $62.3 \%$; 95\% CI [51.6-71.3]) than with q1w cisplatin (5 years OS: 52.6\%; 95\% CI [44.5-60.0]) (log-rank $P=0.0146$ ). More number of patients treated according to the $\mathrm{q} 1 \mathrm{w}$ schedule experienced a recurrence: $47.3 \%$ vs $30.9 \%(P=0.009)$. Thus, the PFS for q3w schedule was found to be globally better ( 5 years PFS: $55.8 \%$; 95\% CI [45.0-65.3]) than for q1w schedule (5 years PFS: 43.6\%; 95\% CI [35.9-51.0]) (log-rank $P=0.0161)$. However, both multivariate analyses, OS and PFS, produce no significant hazard ratio for chemo-radiotherapy modality once adjusted on unbalanced covariates according to the descriptive analysis.

Conclusion: Though q1w seemed to be safer than $\mathrm{q} 3 \mathrm{w}$ according to the descriptive analysis, multivariate analyses failed to conclude about its efficiency. Therefore, we conclude that the q3w schedule should remain the standard and prospective comparisons are needed.

Keywords: head and neck cancer, radiotherapy potentiation, chemoradiation, cisplatin

\section{Introduction}

The incidence of head and neck squamous cell carcinoma (HNSCC) in the western countries is approximately 120,000 patients $^{1}$ with approximately two-thirds of locoregionally 
advanced head and neck squamous cell carcinoma (LAHNSCC). Radiotherapy (RT) is a major pillar of treatment for LAHNSCC and is given as exclusive treatment or as adjuvant treatment after surgery. ${ }^{2}$ For both adjuvant and exclusive treatment, chemoradiotherapy (CT-RT) with every 3 weeks cisplatin (q3w) at a dose of $100 \mathrm{mg} / \mathrm{m}^{2}$ at days 1, 22, and 43 gives better overall survival (OS) than RT alone in several Phase III studies. ${ }^{3-6}$ It is confirmed in a large meta-analysis on 50 concomitant trials: the hazard ratio (HR) for OS was 0.81 (95\% confidence interval [CI] [0.78-0.86], $P<0.0001)$ with an absolute benefit of $6.5 \%$ at 5 years in favor of CT-RT vs RT alone. ${ }^{7}$ However, this increased OS was associated with an increased toxicity. For example, in an adjuvant study, the rate of grade 3/4 acute toxicities was increased from $34 \%$ with RT alone to $77 \%$ $(P<0.001)$ with CT-RT. ${ }^{5}$ The late toxicity increased in the q3 w schedule compared with the q1w schedule. Although only few data are published, a small study reported $47 \%$ of grade $3 / 4$ late toxicities in the RT group against $82 \%(P=0.02)$ in the CT-RT group. ${ }^{8}$

Indeed, the major requirement now is to decrease the toxicity associated with CT-RT without altering its efficacy. The three major tumor types for which radiation is potentialized by cisplatin are HNSCC, undifferentiated nasopharyngeal carcinoma (UCNT), and cervical cancers. For the two later localizations, weekly cisplatin (q1w) at the dose of $40 \mathrm{mg}$ / $\mathrm{m}^{2}$ is the standard potentiation, even though no direct comparison was done with the $\mathrm{q} 3 \mathrm{w}$ cisplatin. ${ }^{9-14}$ For UCNT, q1w cisplatin was feasible and seemed to be less toxic than $\mathrm{q} 3 \mathrm{w}$ cisplatin. In terms of OS, a Phase III study demonstrated that RT-CT with q1w cisplatin compared to RT alone increased the 5 years OS from 59\% (95\% CI [50.9-66.2]) to 70\% (95\% CI [63.4-7.3]) on locoregionally advanced nasopharyngeal carcinoma $(\mathrm{HR}=0.71,95 \% \mathrm{CI}$ [0.50-1.00], $P=0.049) .{ }^{11}$ In two meta-analyses consisting of eight trials with 1,753 patients and 19 trials with 4,798 patients demonstrated a HR of $0.82(95 \% \text { CI [0.71-0.95], } P=0.006)^{9}$ and an absolute benefit of $6.5 \%$ at 5 years, respectively. ${ }^{10}$ This benefit of $6.5 \%$ was similar to the benefit obtained by using $\mathrm{q} 3 \mathrm{w}$ cisplatin in LAHNSCC. ${ }^{7}$ Although no study demonstrated equivalence or noninferiority of weekly cisplatin compared to $\mathrm{q} 3 \mathrm{w}$ cisplatin as potentiation for RT in head and neck cancer, the q1w schedule is largely used due to its lower toxicity as it is expected to have efficacy similar to that of the $\mathrm{q} 3 \mathrm{w}$ schedule.

This study was designed to assess to what extent should $\mathrm{q} 1 \mathrm{w}$ cisplatin replace the $\mathrm{q} 3 \mathrm{w}$ schedule, to obtain similar survival results and better tolerability, and can be a basis for a randomized study.

\section{Patients and methods Retrieval procedure and selection of patient records}

The data of all patients without metastasis with histologically confirmed LAHNSCC, irradiated with concurrent cisplatin ( $\mathrm{q} 1 \mathrm{w}$ or $\mathrm{q} 3 \mathrm{w}$ ) in our institution (Centre Léon Bérard, Lyon, France) between January 2004 and December 2008, were retrospectively reviewed. Patients received an exclusive RT or RT after surgery and/or induction chemotherapy.

Collection of patients' data was in rules with CNIL (Commission nationale de l'informatique et des libertés, French authority to protect the use of patients' data) and the confidentiality of the patients was preserved. This study was authorized by the ethics committee of the Centre Léon Bérard (Lyon, France).

\section{Treatment}

RT was delivered over a 7-week period using conventional fractionation (total dose, 60-70 Gy). Generally, RT starts 3-7 weeks after completion of chemotherapy or surgery. Q3w chemotherapy was planned to be delivered $\left(100 \mathrm{mg} / \mathrm{m}^{2}\right)$ at days 1,22 , and 43 from the start of RT, whereas q1w cisplatin $\left(40 \mathrm{mg} / \mathrm{m}^{2}\right)$ was planned to be delivered each week during the RT treatment. Patients were hospitalized $24-48$ hours for q3w cisplatin administration, and an intravenous hyperhydration with $2 \mathrm{~L} / \mathrm{m}^{2}$ of $0.9 \% \mathrm{NaCl}$ or $5 \%$ glucose (with $2 \mathrm{~g} / \mathrm{L} \mathrm{KCl}$ and $4 \mathrm{~g} / \mathrm{L} \mathrm{NaCl}$ ) was given; in the q1w schedule, cisplatin was administered ambulatory with $1 \mathrm{~L}$ intravenous hydration and devices for orally hydration at home. All patients received adequate antiemetic prophylaxis. The choice between $\mathrm{q} 1 \mathrm{w}$ and $\mathrm{q} 3 \mathrm{w}$ was left to the appraisal of the radiotherapist, which was largely subjective and needed a multivariate analysis, but the considerations were age, weight loss before radiation, creatinine clearance, performance status, and the use of induction chemotherapy. In practice, such radiotherapists use systematically $\mathrm{q} 1 \mathrm{w}$ cisplatin, and other radiotherapists use q3w cisplatin. In case of poor CT-RT tolerability, the patients could be re-hospitalized or receive a nasogastric intubation.

\section{Statistical analysis}

Study population was first described and data were compared between CT-RT groups (q1w vs q3w) using Student's $t$-test or nonparametrical Wilcoxon's test for continuous data and Pearson's chi-square test or Fisher's exact test for categorical data.

Then, OS and progression-free survival (PFS) analyses were performed. Because of the presence of many comorbidities in the patients with LAHNSCC, time to progression (TTP) study was also done to compare the CT-RT schedules ( $\mathrm{q} 1 \mathrm{w}$ and $\mathrm{q} 3 \mathrm{w}$ ). 
OS was defined as the time from RT onset to the date of death (due to any cause) or date of last follow-up (for censored patients); PFS as the time from RT onset to the date of recurrence (local or metastatic) or death (due to any cause) or date of last follow-up (for censored patients); and TTP as the time from RT onset to the date of recurrence (local or metastatic) or death due to cancer or date of last follow-up (for censored patients). Survival distributions were estimated by Kaplan-Meier method and compared between CT-RT groups using the log-rank test. Prognostic effect of CT-RT group was explored using proportional hazard Cox model. As the purpose of this study was to estimate the potential effect of the CT-RT modality ( $\mathrm{q} 1 \mathrm{w}$ or $\mathrm{q} 3 \mathrm{w}$ ) on survival, the strategy of modeling implemented consisted in adjusting this variable on the unbalanced covariates revealed by the descriptive analysis, as they may be the confounding factors. All interactions between the type of CT-RT and these variables were also tested and incorporated into the multivariate model (if significant at 5\% level).

All analyses were performed using the SAS software version 9.3 (SAS institute Inc, Cary, NC, USA).

\section{Results}

\section{Patients' characteristics}

Between January 2004 and December 2008, 165 patients without metastasis with LAHNSCC received chemoradiation with q1w cisplatin and 97 with $\mathrm{q} 3 \mathrm{w}$ cisplatin in a single institution (Centre Léon Bérard) and were retrospectively included in our study.

The characteristics of patients and tumors are summarized in Table 1 . About half of the patients (47.9\%) had oropharyngeal cancer and $38.3 \%$ received induction chemotherapy (33.9\% of patients were treated with q1w CT-RT and $45.8 \%$ with q3w CT-RT) without significant difference at 5\% level $(P=0.057)$.

Six characteristics were significantly different between patients treated with $\mathrm{q} 1 \mathrm{w}$ and $\mathrm{q} 3 \mathrm{w}$ CT-RT: median age at treatment initiation (58.5 [min-max: 33.6-79.7] vs 54.4 years old [19.4-70.7], respectively; $P<0.001$ ), alcohol consumption ( $80 \%$ vs $68.4 \% ; P=0.039$ ), stage IV at diagnosis (60.6\% vs $80.2 \% ; P=0.002)$, median weight before RT (65 kg [min-max: 39-105] vs $71 \mathrm{~kg}$ [37.5-140]; $P=0.021)$, median clearance of creatinine before RT $(91 \mathrm{~mL} / \mathrm{min}$ [min-max: 39-358] vs $104 \mathrm{~mL} / \mathrm{min}$ [46-248]; $P=0.003)$, and radiation as adjuvant treatment $(74.5 \%$ vs $62.9 \% ; P=0.046)$.

\section{Toxicity of the chemoradiation}

Data about toxicities of chemoradiation and their management are summarized in Tables 2 and 3, respectively.
Table I Characteristics of patients and tumors at the onset of radiotherapy

\begin{tabular}{|c|c|c|c|}
\hline & $\begin{array}{l}\text { q I w cisplatin } \\
(\mathrm{N}=165)\end{array}$ & $\begin{array}{l}\text { q3w cisplatin } \\
(\mathrm{N}=97)\end{array}$ & Test \\
\hline \multicolumn{4}{|c|}{ Age at treatment initiation (years) } \\
\hline Median (range) & $58.5(33.6-79.7)$ & $54.4(19.4-70.7)$ & $P<0.001$ \\
\hline \multicolumn{4}{|l|}{ Sex } \\
\hline Male & I 44 (87.3\%) & $83(85.6 \%)$ & $P=0.695$ \\
\hline \multicolumn{4}{|l|}{ Performance status } \\
\hline 0 & $59(47.6 \%)$ & $35(47.3 \%)$ & \multirow[t]{6}{*}{$P=0.424$} \\
\hline I & $54(43.5 \%)$ & $33(44.6 \%)$ & \\
\hline 2 & II (8.9\%) & $4(5.4 \%)$ & \\
\hline 3 & - & $\mathrm{I}(\mathrm{I} .4 \%)$ & \\
\hline 4 & - & I (I.4\%) & \\
\hline Unknown & 41 & 23 & \\
\hline \multicolumn{4}{|l|}{ Consumptions } \\
\hline Alcohol & $124 / 155$ (80\%) & $65 / 95(68.4 \%)$ & $P=0.039$ \\
\hline Tobacco & I44/I59 (90.6\%) & $83 / 95(87.4 \%)$ & $P=0.424$ \\
\hline \multicolumn{4}{|c|}{ History of head and neck cancer } \\
\hline & $12(7.3 \%)$ & $2(2.1 \%)$ & $P=0.089$ \\
\hline \multicolumn{4}{|c|}{ Weight before treatment $(\mathrm{kg})$} \\
\hline Median (range) & $65(39-105)$ & $7 \mid(37.5-140)$ & $P=0.021$ \\
\hline \multicolumn{4}{|c|}{ Clearance of creatinine before treatment $(\mathrm{mL} / \mathrm{min})$} \\
\hline Median (range) & $91(39-358)$ & $104(46-248)$ & $P=0.003$ \\
\hline \multicolumn{4}{|c|}{ Localization of tumor } \\
\hline Oral cavity & $24(14.6 \%)$ & $13(13.4 \%)$ & $P=0.862$ \\
\hline Oropharynx & $81(49.4 \%)$ & $44(45.4 \%)$ & \\
\hline Hypopharynx & $27(16.5 \%)$ & 17 (I7.5\%) & \\
\hline Larynx & $29(17.7 \%)$ & $22(22.7 \%)$ & \\
\hline Others & $3(1.8 \%)$ & $\mathrm{I}(\mathrm{I} \%)$ & \\
\hline Unknown & I & - & \\
\hline \multicolumn{4}{|c|}{ Stage of the disease } \\
\hline 1 & $4(2.4 \%)$ & - & $P=0.002$ \\
\hline$\|$ & II (6.7\%) & $7(7.3 \%)$ & \\
\hline III & $50(30.3 \%)$ & $12(12.5 \%)$ & \\
\hline $\mathrm{IVa}$ and IVb & $100(60.6 \%)$ & 77 (80.2\%) & \\
\hline Unknown & - & 1 & \\
\hline \multicolumn{4}{|c|}{ Type of chemoradiation } \\
\hline Exclusive & $42(25.5 \%)$ & $36(37.1 \%)$ & $P=0.046$ \\
\hline Adjuvant & $123(74.5 \%)$ & $6 \mathrm{I}(62.9 \%)$ & \\
\hline \multicolumn{4}{|c|}{ Prior neoadjuvant chemotherapy } \\
\hline Yes & $56(33.9 \%)$ & $44(45.8 \%)$ & $P=0.057$ \\
\hline No & $109(66.1 \%)$ & $52(54.2 \%)$ & \\
\hline Unknown & - & 1 & \\
\hline
\end{tabular}

Abbreviations: $q \mid w$, once weekly; $q 3 w$, every 3 weeks.

As expected, the $\mathrm{q} 3 \mathrm{w}$ potentiation was significantly more toxic when compared with q1w in terms of weight loss $(85.4 \%$ vs $74.2 \% ; P=0.010)$, grade $3 / 4$ mucositis (34\% vs $12.1 \%$; $P<0.001)$, dermatitis ( $7.2 \%$ vs $1.2 \% ; P=0.014)$, and decrease of creatinine clearance (median variation between the beginning and the end of RT in $\mathrm{mL} / \mathrm{min}:-19.4$ [range: -191.9 ; 14.3] vs -7.1 [range: $-69 ; 79.6$ ], $P<0.001)$. More number of patients in q3w group needed analgesics (90.8\% vs $71.4 \%$; $P=0.002)$, secondary hospitalization $(30.9 \%$ vs $7.9 \%$; $P<0.001)$, interruption of RT for more than 3 days $(7.4 \%$ 
Table 2 Toxicity of chemoradiation

\begin{tabular}{|c|c|c|c|}
\hline & $\begin{array}{l}\text { qIw cisplatin } \\
(N=165)\end{array}$ & $\begin{array}{l}\text { q3w cisplatin } \\
(\mathrm{N}=97)\end{array}$ & Test \\
\hline \multicolumn{4}{|l|}{ Mucositis } \\
\hline All grades & $101(61.2 \%)$ & $85(87.6 \%)$ & $P<0.00$ I \\
\hline Grade 3-4 & $20(12.1 \%)$ & $33(34 \%)$ & $P<0.00$ I \\
\hline \multicolumn{4}{|l|}{ Dermatitis } \\
\hline All grades & $76(46.1 \%)$ & 71 (73.2\%) & $P<0.001$ \\
\hline Grade 3-4 & $2(1.2 \%)$ & $7(7.2 \%)$ & $P=0.014$ \\
\hline \multicolumn{4}{|l|}{ Nausea/vomiting } \\
\hline All grades & $34(20.6 \%)$ & $50(51.5 \%)$ & $P<0.001$ \\
\hline Grade 3-4 & $4(2.4 \%)$ & $4(4.1 \%)$ & $P=0.473$ \\
\hline \multicolumn{4}{|c|}{ Transitory renal failure } \\
\hline All grades & $5 \mathrm{I} / \mathrm{I} 4 \mathrm{I}(36.2 \%)$ & $45 / 90(50 \%)$ & $P=0.038$ \\
\hline Grade 3-4 & $2 / 14 \mid(1.4 \%)$ & $2 / 90(2.2 \%)$ & $P=0.644$ \\
\hline \multicolumn{4}{|c|}{ Variation of creatinine clearance during $\mathrm{RT}(\mathrm{mL} / \mathrm{min})$} \\
\hline \multirow[t]{2}{*}{ Median (range) } & $\mathrm{n}=125$ & $\mathrm{n}=86$ & $P<0.001$ \\
\hline & $7.1(69.0-79.6)$ & $19.4(191.9-14.3)$ & \\
\hline \multicolumn{4}{|l|}{ Dysphagia } \\
\hline All grades & $79 / 164$ (48.2\%) & $62(63.9 \%)$ & $P=0.014$ \\
\hline Grade 3-4 & $20 / 164(12.2 \%)$ & $13(13.4 \%)$ & $P=0.777$ \\
\hline \multicolumn{4}{|l|}{ Weight loss } \\
\hline Yes & $12 \mathrm{I} / 163(74.2 \%)$ & $82 / 96(85.4 \%)$ & $P=0.010$ \\
\hline Median (range) & $3(12-4)$ & $4(20-3.5)$ & $P=0.002$ \\
\hline \multicolumn{4}{|c|}{ Other grade $3-4$ toxicities } \\
\hline Yes & $14 / 66(2 \mid .2 \%)$ & I7/46 (37.0\%) & $P=0.067$ \\
\hline
\end{tabular}

Abbreviations: qIw, once weekly; q3w, every 3 weeks; RT, radiotherapy.

vs $1.8 \% ; P=0.040)$, and also interruption of chemotherapy ( $43.8 \%$ vs $30.3 \% ; P=0.028$ ). Finally, only $42.2 \%$ of patients in the $\mathrm{q} 3 \mathrm{w}$ group received chemotherapy as planned vs $66.7 \%$ in the $\mathrm{q} 1 \mathrm{w}$ group $(P<0.001)$. But no significant difference was noticed in terms of high-grade renal failure, nausea/ vomiting, dysphagia, and nutritional support.

Table 3 Management of the toxicities due to chemoradiation

\begin{tabular}{|c|c|c|}
\hline $\begin{array}{l}\text { q I w cisplatin } \\
(\mathrm{N}=165)\end{array}$ & $\begin{array}{l}\text { q3w cisplatin } \\
(\mathrm{N}=97)\end{array}$ & Test \\
\hline \multicolumn{3}{|c|}{ Temporary discontinuation of RT for toxicity } \\
\hline $9(5.5 \%)$ & II (II.3\%) & $P=0.083$ \\
\hline \multicolumn{3}{|c|}{ Temporary arrest of $\mathrm{RT} \geq 3$ days } \\
\hline $3 / 164(1.8 \%)$ & $7 / 94(7.4 \%)$ & $P=0.040$ \\
\hline \multicolumn{3}{|c|}{ Arrest of $\mathrm{CT}$ during $\mathrm{RT}$} \\
\hline $50(30.3 \%)$ & $42 / 96(43.8 \%)$ & $P=0.028$ \\
\hline \multicolumn{3}{|c|}{ Completion as planned of CT } \\
\hline $86 / 129(66.7 \%)$ & $35 / 83(42.2 \%)$ & $P<0.001$ \\
\hline \multicolumn{3}{|c|}{ Secondary hospitalization } \\
\hline $13 / 164(7.9 \%)$ & $30(30.9 \%)$ & $P<0.001$ \\
\hline \multicolumn{3}{|l|}{ Use of analgesics } \\
\hline 65/9I (7I.4\%) & $69 / 76(90.8 \%)$ & $P=0.002$ \\
\hline \multicolumn{3}{|c|}{ Need of nutritional support } \\
\hline $4 \mathrm{I} / 83(49.4 \%)$ & $33 / 58(56.9 \%)$ & $P=0.380$ \\
\hline
\end{tabular}

Abbreviations: $\mathrm{qIw}$, once weekly; $\mathrm{q} 3 \mathrm{w}$, every 3 weeks; RT, radiotherapy; $\mathrm{CT}$, chemotherapy.

\section{Survival analysis}

With a median follow-up of 73 months ( $95 \%$ CI [68.9-76.2]) and 125 deaths $(47.7 \%)$ registered $(38.1 \%$ and $53.3 \%$ on $\mathrm{q} 3 \mathrm{w}$ and $\mathrm{q} 1 \mathrm{w}$ group, respectively), the 3 years OS and the 5 years OS rates for all the patients were $63.9 \%(95 \% \mathrm{CI}$ [57.6-69.5]) and 56.2\% (95\% CI [49.8-62]), respectively. OS was studied according to the type of potentiation, a significant difference in OS was found between the $\mathrm{q} 1 \mathrm{w}$ and the $\mathrm{q} 3 \mathrm{w}$ schedules (log-rank $P=0.0146$ ), in favor of the $\mathrm{q} 3 \mathrm{w}$ schedule with 3 years OS rate of $71.3 \%$ (95\% CI [61-79.3]) vs $59.6 \%$ for q1w group (95\% CI [51.6-66.7]) and a 5 years OS rate of $62.3 \%(95 \%$ CI [51.6-71.3]) as against $52.6 \%$ (95\% CI [44.5-60]) for the patients treated with q1w (Figure 1).

More number of patients treated according to the $\mathrm{q} 1 \mathrm{w}$ schedule experienced a recurrence of their disease, $47.3 \%$ $(\mathrm{n}=78)$ vs $30.9 \%(\mathrm{n}=30)$ for the patients treated with $\mathrm{q} 3 \mathrm{w}$ cisplatin $(P=0.009)$. The 3 years PFS and the 5 years PFS rates for all the patients were $56.2 \%$ (95\% CI [49.9-62]) and $48.1 \%$ (95\% CI [41.8-54]), respectively. PFS, studied according to the type of potentiation, was significantly in favor of the $\mathrm{q} 3 \mathrm{w}$ schedule ( $\log$-rank $P=0.0161)$ with 3 years PFS rate of $62.9 \%$ for the $\mathrm{q} 3 \mathrm{w}$ group (95\% CI [52.3-71.7]) vs $52.3 \%$ for the q1w group (95\% CI [44.4-59.7]) and 5 years PFS rate of $55.8 \%$ for the q3w group $(95 \% \mathrm{CI}$ [45-65.3]) vs $43.6 \%$ for the $\mathrm{q} 1 \mathrm{w}$ group ( $95 \%$ CI [35.9-51]) (Figure 2).

Since patients with LAHNSCC have a lot of comorbidities, the TTP should also be a good parameter to compare the two schedules. Among the 125 deceased patients, 88 died of cancer whereas 37 died of comorbidities. The 88 patients who died of cancer had previously relapsed. The 3 years and the 5 years TTP rates for all the patients were $64.0 \%$ (95\% CI [57.7-69.7]) and 57.8\% (95\% CI [51.3-63.9]), respectively. By taking the type of potentiation into consideration, TTP univariate analysis favored the $\mathrm{q} 3 \mathrm{w}$ schedule (log-rank $P=0.0072)$ with a 3 years TTP rate of $71.9 \%(95 \%$ CI [61.4-79.9]) vs $59.4 \%$ for patients treated with q1w $(95 \%$ CI [51.2-66.7]) and 5 years TTP rate of $68.9 \%(95 \%$ CI [58.1-77.5]) vs $51.4 \%$ for q1w group (95\% CI [43.1-59.1]) (Figure 3).

In order to assess the relationship between survival rates (OS, PFS, and TTP) and CT-RT group, by taking into account the differences between the two groups revealed by the comparative description of study population, a multivariate Cox model was built to estimate CT-RT group effect by adjusting on the following potential confounding factors: age at RT initiation, alcohol consumption, prior neoadjuvant 


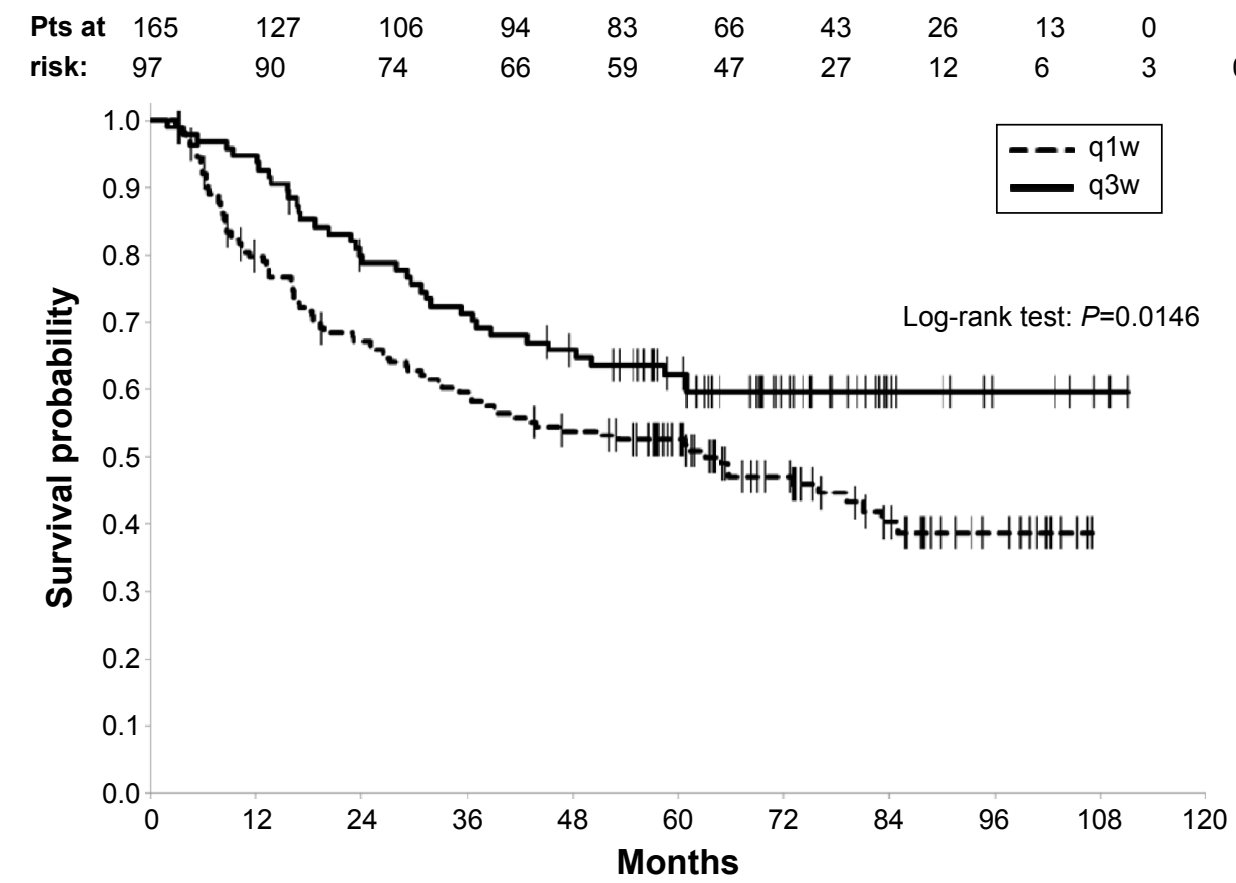

Figure I Overall survival according to the type of chemotherapy.

Abbreviations: qlw, once weekly; q3w, every 3 weeks; pts, patients.

chemotherapy (CT), type of chemoradiation (exclusive or adjuvant), weight and clearance of creatinine (renal failure or not) before treatment, and tumor stage ( $\mathrm{T}$ and $\mathrm{N}$ of the TNM classification). Finally, OS multivariate analysis revealed no significant prognostic effect on the CT-RT group.
In the same way, the tendency of a deleterious effect of q1w on survival was not confirmed by PFS or TTP multivariate analyses. Results regarding the analysis done on the subgroup of patients who did not receive induction chemotherapy $(\mathrm{n}=161)$ are similar.

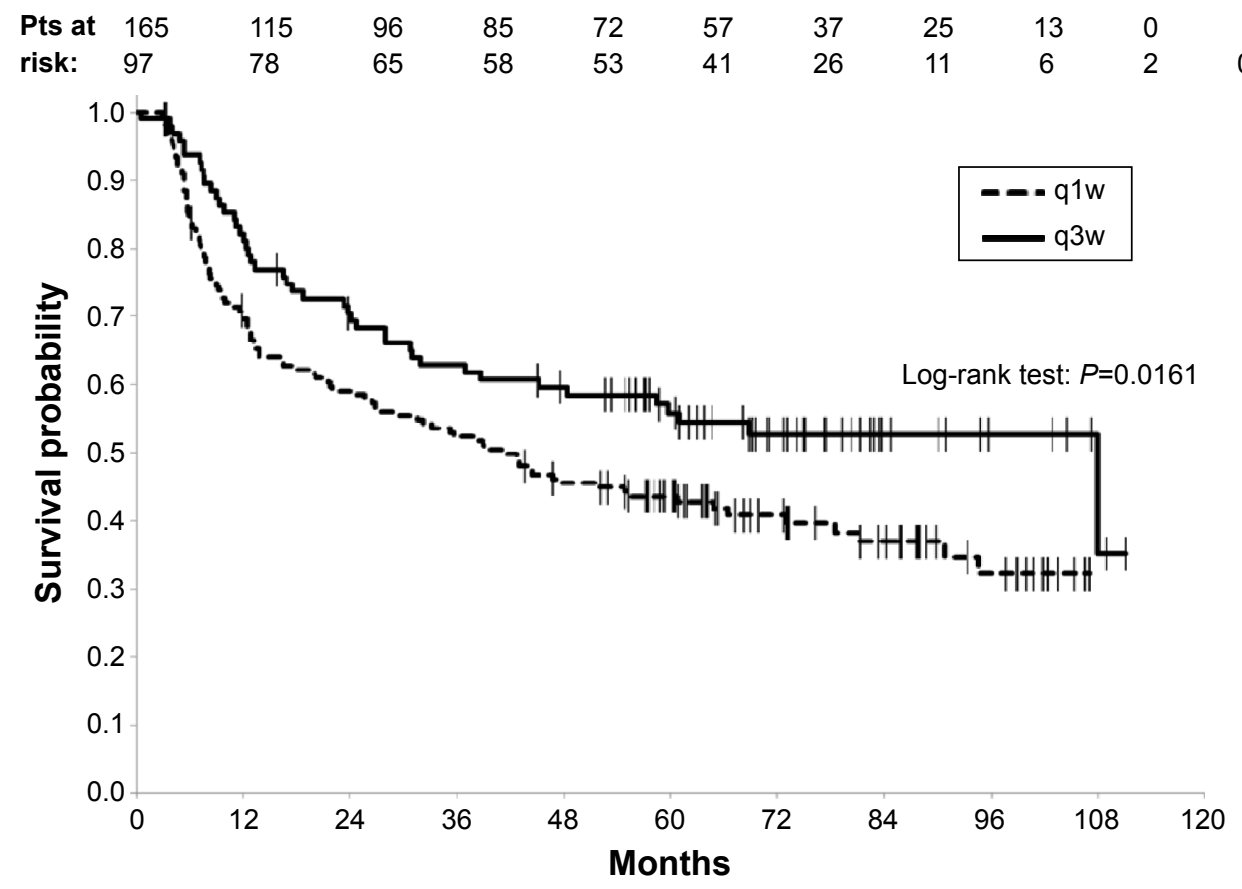

Figure 2 Progression-free survival according to the type of chemotherapy. Abbreviations: qlw, once weekly; q3w, every 3 weeks; pts, patients. 


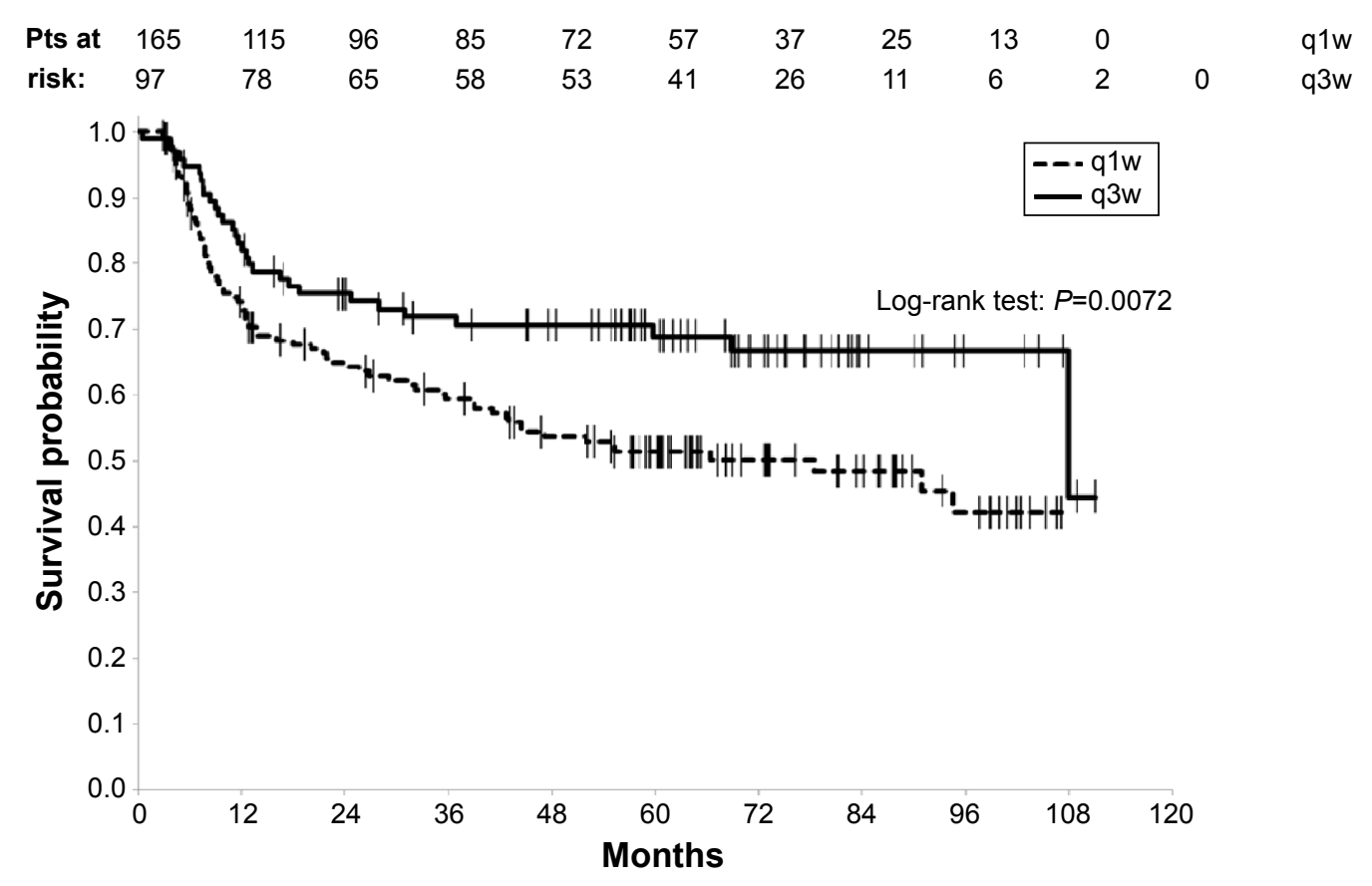

Figure 3 Time to progression according to the type of chemotherapy. Abbreviations: qIw, once weekly; q3w, every 3 weeks; pts, patients.

\section{Discussion}

Our study is consistent with the previously published monoarm studies which demonstrated that weekly cisplatin concurrent with RT is well tolerated. ${ }^{15-22}$ In this study, the largest published to date, weekly cisplatin is significantly better tolerated than $\mathrm{q} 3 \mathrm{w}$ cisplatin. It is confirmed by only one comparative study, ${ }^{23}$ whereas three did not show any difference ${ }^{24-26}$ and one found $3 \mathrm{qw}$ schedule to be less toxic. ${ }^{27}$

Even if weekly cisplatin is probably less toxic than q3w administration, which is presently the standard treatment, our survival results are consistent with the idea that the $\mathrm{q} 3 \mathrm{w}$ administration should remain the standard. At the first look the trend according to which the OS (and PFS and TTP) would be better on patients treated by $\mathrm{q} 3 \mathrm{w}$ schedule to the detriment of those weekly treated (q1w) was quite strong according to the Kaplan-Meier curves. However, this tendency (out of favor of the experimental arm [q1w schedule]) was not confirmed (at 5\% level) according to the results of the multivariate Cox models.

As this study is both monocentric and retrospective, these results may just reflect one's own practice and may suffer from a selection bias that can affect the constitution of the two CT-RT groups, since the clinical reality of a patient guides the indication of CT-RT ( $\mathrm{q} 3 \mathrm{w}$ or $\mathrm{q} 1 \mathrm{w}$ ). A plausible hypothesis would be that $\mathrm{q} 3 \mathrm{w}$ treatment plan is priority intended for patients expected to support such boost of chemotherapy and let $\mathrm{q} 1 \mathrm{w}$ to weaker patients.
In fact, as the descriptive analysis illustrates, the patients who received the $\mathrm{q} 1 \mathrm{w}$ chemotherapy presented more deleterious baseline characteristics than the patients treated every 3 weeks ( $\mathrm{q} 3 \mathrm{w})$ : older and slimmer patients before RT onset, more alcohol consumers, more renal failure before RT. On the contrary, patients of the $\mathrm{q} 3 \mathrm{w}$ arm presented more advanced tumors (stage IV) and node involvement at diagnosis. These differences constitutes a major limitation that prevents us from demonstrating in a formal way the potential substitutability of the weekly chemotherapy to the chemotherapy administered every 3 weeks. For that purpose, a randomized and comparative trial, to insure the comparability between the groups (which is lacking in this study), would be necessary.

When our results were compared to those of the literature, we noticed that the absolute survival difference between the two CT-RT groups of approximately $10 \%$, at least found here (5 years OS, PFS, and TTP rates), was similar to that observed in a meta-analysis which assessed the benefit of chemoradiation against $\mathrm{RT}$ alone, ${ }^{7}$ suggesting that $\mathrm{q} 1 \mathrm{w}$ cisplatin could be of limited interest. But, as said, the two groups in our study are not well balanced and no definitive conclusion could be drawn on the basis of our results. There is no convincing comparative study in the literature to assess the equivalence of $\mathrm{q} 1 \mathrm{w}$. Indeed, the five published studies dedicated to that subject did not demonstrate any difference in terms of efficacy, but they included only approximately $50^{24-27}$ or $94^{23}$ patients. 
On the other hand, mono-arm studies were conducted and results were compared with historical data of 3 qw cisplatin: five studies seemed to be in favor of $\mathrm{q} 1 \mathrm{w},{ }^{15,16,18-20}$ one was with deleterious effects, ${ }^{21}$ and one was without benefit. ${ }^{17}$ In this last study, which included 103 patients retrospectively, there was no cumulative effect of the dose of cisplatin, suggesting again that weekly cisplatin could be of little interest when compared with RT alone. The only comparative study that demonstrated significant benefit of weekly cisplatin added to RT vs RT alone included only 83 patients, ${ }^{22}$ which is not sufficient to assess a new standard. Hence, for eligible patients the $\mathrm{q} 3 \mathrm{w}$ schedule should remain the gold standard. In order to decrease the toxicity of $\mathrm{q} 3 \mathrm{w}$ cisplatin, we launched a program in our institution to perfuse patients at home for 5 days after chemotherapy with $1 \mathrm{~L}$ of $\mathrm{NaCl}$ at the night.

On the contrary to HNSCC, the potentiation of radiation by weekly cisplatin at the dose of $40 \mathrm{mg} / \mathrm{m}^{2}$ is a validated standard for squamous cervical cancer ${ }^{12-14}$ and undifferentiated carcinoma of the nasopharynx (UCNT). ${ }^{11}$ For UCNT, other studies demonstrated the benefit of the 3 qw cisplatin ${ }^{28}$ or high-dose scheme, ${ }^{29}$ but no direct comparative studies are available to attest the superiority of one schedule or their equivalence.

Since no large trial validated the superiority of weekly cisplatin potentiation compared with RT alone, it remains unclear as to which type of potentiation should be proposed to patients ineligible for $3 \mathrm{qw}$ cisplatin. Weekly carboplatin was not validated. ${ }^{29,30}$ The combination of carboplatin and fluorouracil brings positive results but is also toxic and probably not indicated for patients ineligible to $\mathrm{q} 3 \mathrm{w}$ cisplatin. ${ }^{4}$ Cetuximab should be considered since it is superior to exclusive RT alone. ${ }^{31}$ But it did not demonstrate significant benefit for patients older than 65 years, the most numerous candidates for potentiation other than $\mathrm{q} 3 \mathrm{w}$. For eligible patients, no direct study compared exclusive RT potentiated by $\mathrm{q} 3 \mathrm{w}$ cisplatin or cetuximab. Presently, the only indirect monocentric study suggests that cetuximab is not as efficient, but this small retrospective study cannot bring definitive response. ${ }^{32}$ For adjuvant RT, cetuximab has no authorization. After induction chemotherapy, cetuximab could be as efficient as $\mathrm{q} 3 \mathrm{w}$ cisplatin for early local control, ${ }^{33}$ but no potentiation (cisplatin or cetuximab) demonstrated any superiority to RT alone.

\section{Conclusion}

To conclude, the temptation of potentiation of RT for LAHNSCC with q1w cisplatin, in order to decrease the toxicity and increase the future quality of life, should not be recommended outside clinical trials, since our results do not suggest any strong survival improvement. That encourages us to consider the use of weekly cisplatin with very high precaution for the moment and to powerfully explore $\mathrm{q} 3 \mathrm{w}$ alternatives, thanks to the large comparative clinical trials. In routine practice, if patients are fit, $\mathrm{q} 3 \mathrm{w}$ cisplatin should remain the standard potentiation of RT for LAHNSCC.

\section{Disclosure}

The authors report no conflicts of interest in this work.

This paper was presented at the 2013 ASCO annual meeting as a poster presentation with interim findings. The poster's abstract was published in "Poster Abstracts" in J Clin Oncol. 31, 2013 (suppl; abstr 6056): http://meetinglibrary. asco.org/content/112388-132. The actual paper, however, has never been published.

\section{References}

1. Jemal A, Siegel R, Ward E, Hao Y, Xu J, Thun MJ. Cancer statistics. CA Cancer J Clin. 2009;59:225-249.

2. Saunders MI, Rojas AM. Management of cancer of the head and necka cocktail with your PORT? N Engl J Med. 2004;350:1997-1999.

3. Bernier J, Domenge C, Ozsahin M, et al. Postoperative irradiation with or without concomitant chemotherapy for locally advanced head and neck cancer. N Engl J Med. 2004;350:1945-1952.

4. Bourhis J, Sire C, Graff P, et al. Concomitant chemoradiotherapy versus acceleration of radiotherapy with or without concomitant chemotherapy in locally advanced head and neck carcinoma (GORTEC 99-02): an open-label phase 3 randomised trial. Lancet Oncol. 2012;13: 145-153.

5. Cooper JS, Pajak TF, Forastiere AA, et al. Postoperative concurrent radiotherapy and chemotherapy for high-risk squamous-cell carcinoma of the head and neck. N Engl J Med. 2004;350:1937-1944.

6. Forastiere AA, Goepfert H, Maor M, et al. Concurrent chemotherapy and radiotherapy for organ preservation in advanced laryngeal cancer. N Engl J Med. 2003;349:2091-2098.

7. Pignon JP, le Maitre A, Maillard E, Bourhis J. Meta-analysis of chemotherapy in head and neck cancer (MACH-NC): an update on 93 randomised trials and 17,346 patients. Radiother Oncol. 2009;92:4-14.

8. Denis F, Garaud P, Bardet E, et al. Late toxicity results of the GORTEC 94-01 randomized trial comparing radiotherapy with concomitant radiochemotherapy for advanced-stage oropharynx carcinoma: comparison of LENT/SOMA, RTOG/EORTC, and NCI-CTC scoring systems. Int J Radiat Oncol Biol Phys. 2003;55:93-98.

9. Baujat B, Audry H, Bourhis J, et al. Chemotherapy as an adjunct to radiotherapy in locally advanced nasopharyngeal carcinoma. Cochrane Database Syst Rev. 2006;4:CD004329.

10. Blanchard $\mathrm{P}$, Lee AW, Leclercq J, et al. Meta-analysis of chemotherapy in nasopharyngeal carcinoma (MAC-NPC): an update on 4,798 patients. J Clin Oncol (ASCO meeting). 2014; Abstract 6022.

11. Chan AT, Leung SF, Ngan RK, et al. Overall survival after concurrent cisplatin-radiotherapy compared with radiotherapy alone in locoregionally advanced nasopharyngeal carcinoma. J Natl Cancer Inst. 2005; 97(7):536-539.

12. Keys HM, Bundy BN, Stehman FB, et al. Cisplatin, radiation, and adjuvant hysterectomy compared with radiation and adjuvant hysterectomy for bulky stage IB cervical carcinoma. N Engl J Med. 1999;340: 1154-1161.

13. Morris M, Eifel PJ, Lu J, et al. Pelvic radiation with concurrent chemotherapy compared with pelvic and para-aortic radiation for high-risk cervical cancer. N Engl J Med. 1999;340:1137-1143. 
14. Rose PG, Bundy BN, Watkins EB, et al. Concurrent cisplatin-based radiotherapy and chemotherapy for locally advanced cervical cancer. N Engl J Med. 1999;340:1144-1153.

15. Homma A, Inamura N, Oridate N, et al. Concomitant weekly cisplatin and radiotherapy for head and neck cancer. Jpn J Clin Oncol. 2011;41:980-986.

16. Otty Z, Skinner MB, Dass J, et al. Efficacy and tolerability of weekly low-dose cisplatin concurrent with radiotherapy in head and neck cancer patients. Asia Pac J Clin Oncol. 2011;7:287-292.

17. Steinmann D, Cerny B, Karstens JH, Bremer M. Chemoradiotherapy with weekly cisplatin $40 \mathrm{mg} / \mathrm{m}(2)$ in 103 head-and-neck cancer patients: a cumulative dose-effect analysis. Strahlenther Onkol. 2009; 185:682-688.

18. Rutten H, Pop LA, Janssens GO, et al. Long-term outcome and morbidity after treatment with accelerated radiotherapy and weekly cisplatin for locally advanced head-and-neck cancer: results of a multidisciplinary late morbidity clinic. Int J Radiat Oncol Biol Phys. 2011;81:923-929.

19. Rampino M, Ricardi U, Munoz F, et al. Concomitant adjuvant chemoradiotherapy with weekly low-dose cisplatin for high-risk squamous cell carcinoma of the head and neck: a phase II prospective trial. Clin Oncol (R Coll Radiol). 2011;23:134-140.

20. Watkins JM, Zauls AJ, Wahlquist AH, et al. Low-dose weekly platinum-based chemoradiation for advanced head and neck cancer. Laryngoscope. 2010;120:236-242.

21. Pala M, Odrazka K, Holeckova P, et al. Definitive radiochemotherapy with weekly cisplatin in patients with head and neck cancer; single institution outcome analysis. J BUON. 2012;17:471-477.

22. Bachaud JM, Cohen-Jonathan E, Alzieu C, David JM, Serrano E, Daly-Schveitzer N. Combined postoperative radiotherapy and weekly cisplatin infusion for locally advanced head and neck carcinoma: final report of a randomized trial. Int J Radiat Oncol Biol Phys. 1996;36:999-1004.

23. Espeli V, Zucca E, Ghielmini M, et al. Weekly and 3-weekly cisplatin concurrent with intensity-modulated radiotherapy in locally advanced head and neck squamous cell cancer. Oral Oncol. 2012;48:266-271.

24. Kose F, Besen A, Sumbul T, et al. Weekly cisplatin versus standard three-weekly cisplatin in concurrent chemoradiotherapy of head and neck cancer: the Baskent University experience. Asian Pac J Cancer Prev. 2011;12:1185-1188.
25. Uygun K, Bilici A, Karagol H, et al. The comparison of weekly and three-weekly cisplatin chemotherapy concurrent with radiotherapy in patients with previously untreated inoperable non-metastatic squamous cell carcinoma of the head and neck. Cancer Chemother Pharmacol. 2009;64:601-605

26. Ho KF, Swindell R, Brammer CV. Dose intensity comparison between weekly and 3-weekly Cisplatin delivered concurrently with radical radiotherapy for head and neck cancer: a retrospective comparison from New Cross Hospital, Wolverhampton, UK. Acta Oncol. 2008;47:1513-1518.

27. Tsan DL, Lin CY, Kang CJ, et al. The comparison between weekly and three-weekly cisplatin delivered concurrently with radiotherapy for patients with postoperative high-risk squamous cell carcinoma of the oral cavity. Radiat Oncol. 2012;7:215.

28. Al-Sarraf M, LeBlanc M, Giri PG, et al. Chemoradiotherapy versus radiotherapy in patients with advanced nasopharyngeal cancer: phase III randomized Intergroup study 0099. J Clin Oncol. 1998;16: $1310-1317$.

29. Lin JC, Jan JS, Hsu CY, Liang WM, Jiang RS, Wang WY. Phase III study of concurrent chemoradiotherapy versus radiotherapy alone for advanced nasopharyngeal carcinoma: positive effect on overall and progression-free survival. J Clin Oncol. 2003;21:631-637.

30. Racadot S, Mercier M, Dussart S, et al. Randomized clinical trial of post-operative radiotherapy versus concomitant carboplatin and radiotherapy for head and neck cancers with lymph node involvement. Radiother Oncol. 2008;87:164-172.

31. Bonner JA, Harari PM, Giralt J, et al. Radiotherapy plus cetuximab for locoregionally advanced head and neck cancer: 5-year survival data from a phase 3 randomised trial, and relation between cetuximabinduced rash and survival. Lancet Oncol. 2010;11:21-28.

32. Koutcher L, Sherman E, Fury M, et al. Concurrent cisplatin and radiation versus cetuximab and radiation for locally advanced head-and-neck cancer. Int J Radiat Oncol Biol Phys. 2011;81:915-922.

33. Lefebvre JL, Pointreau Y, Rolland F, et al. Induction chemotherapy followed by either chemoradiotherapy or bioradiotherapy for larynx preservation: the TREMPLIN randomized phase II study. J Clin Oncol. $2013 ; 31: 853-859$
Drug Design, Development and Therapy

\section{Publish your work in this journal}

Drug Design, Development and Therapy is an international, peerreviewed open-access journal that spans the spectrum of drug design and development through to clinical applications. Clinical outcomes, patient safety, and programs for the development and effective, safe, and sustained use of medicines are a feature of the journal, which

\section{Dovepress}

has also been accepted for indexing on PubMed Central. The manuscript management system is completely online and includes a very quick and fair peer-review system, which is all easy to use. Visit http://www.dovepress.com/testimonials.php to read real quotes from published authors. 